\title{
UNRAVELLING THE ORIGIN OF THE
}

\section{YELLOW-ORANGE LUMINESCENCE IN}

\section{NATURAL AND SYNTHETIC SCAPOLITES -}

\section{ELECTRONIC SUPPORTING INFORMATION}

Féodor Blumentritt ${ }^{a}$, Camille Latouche $^{a}$, Yann Morizet $^{a, b}$, Maria-Teresa Caldes $^{a}$, Stéphane Jobic ${ }^{a}$ and Emmanuel Fritsch ${ }^{a *}$

${ }^{a}$ Université de Nantes, CNRS, Institut des Matériaux Jean Rouxel, IMN, F-44000 Nantes, France

${ }^{b}$ Université de Nantes, Nantes Atlantique Universités, Laboratoire de Planétologie et Géodynamique (LPG), UMR CNRS 6112, 2 rue de la Houssinière, 44322 Nantes Cedex, France.

\section{Corresponding Author}

*Emmanuel.fritsch@cnrs-imn.fr

\section{Supporting information table of content:}

\section{Details on natural and synthetic materials}

1.1. Natural sample

1.2. Synthetic samples

\section{Experimental details}

2.1. Chemical analysis 
2.2. X-Ray Diffraction and structure analysis

2.3. Scpectroscopic methods

2.4. Calculation method

3. Caracterization of natural and synthetic samples

3.1. X-Ray Diffraction

3.2. Energy Dispersive X-ray spectrometry

4. Spectroscopic consideration of $\left(\mathrm{S}_{2}\right)^{-}$ions

4.1. Vibronic structure of luminescent analysis

4.2. Infrared spectra

4.3. Raman spectra

4.4. X-ray Photoelectron Spectroscopy analyses

4. References

\section{Details on natural and synthetic materials}

1.1. Natural sample

Nine rough, transparent, near-colorless natural marialite scapolites were analyzed. They all were extracted in Afghanistan. The sample N1 is a gem quality, cut, uncolored, natural scapolite. This sample also come from Afghanistan. It is considered representative and taken for further, longer analyses. Half of it was powdered by smashing it in an agate mortar. 


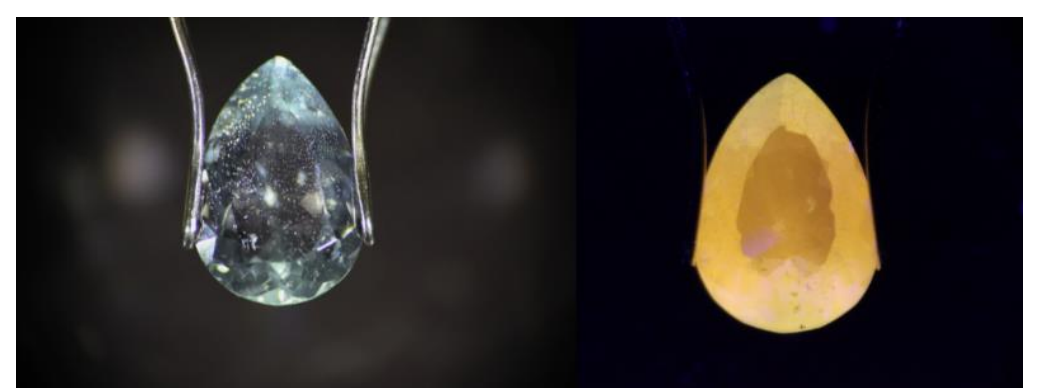

Fig. S1. Example of a natural scapolite under natural light (left) and under $365 \mathrm{~nm}$ UV irradiation (right). Pictures by F. Blumentritt

\subsection{Synthetic samples}

Synthetic scapolite samples have been produced using mixtures of $\mathrm{SiO}_{2}$ (Alfa Aesar, 99.8 \%), $\mathrm{Al}_{2} \mathrm{O}_{3}$ (Fluka, p.a.), $\mathrm{Na}_{2} \mathrm{CO}_{3}$ (Prolabo, $99.5 \%$ ), $\mathrm{NaCl}$ (Alfa Aesar, $99.999 \%$ ) and for some syntheses $\mathrm{Na}_{2} \mathrm{~S}$ (Sigma-Aldrich, $>97 \%$ ). For the S-bearing starting mixture, the $\mathrm{S}$ content in the charge is 1 and 2 wt.\%. All mixtures were prepared following the process described by Almeida et al. ${ }^{1}$. The S-bearing starting mixture was sealed into a Pt capsule. We also used $\mathrm{Au}$ 75-Pd 25 capsule for the synthesis of S-free scapolite sample. Care was taken to avoid any adsorbed water by preparing all mixtures under an inert atmosphere (argon) and keep mixtures in the air-tight oven at $100^{\circ} \mathrm{C}$. We used $3 / 4$ inch talc-pyrex high pressure assemblies. The temperature was recorded during the experiments with B-type (PtRh30-PtRh6) thermocouple. Synthetic sulfur-bearing scapolite were prepared under high pressure $(1.5 \mathrm{GPa})$ and high temperature $\left(975^{\circ} \mathrm{C}\right)$ conditions using piston-cylinder apparatus and following the synthesis method described in Morizet et al. $(2002)^{2}$. The run duration was $48 \mathrm{~h}$ and the run was stopped by cutting-off the power and performing an isobaric quench. Under such intensive conditions $\left(1.5 \mathrm{GPa}\right.$ and $\left.975^{\circ} \mathrm{C}\right)$, Almeida et al. ${ }^{1}$ showed that $\mathrm{S}$-free scapolite mineral phase will be stable. However, we also show that the stability field is not dramatically affected by the presence of small quantity of sulfur in the 
experimental charges as the recovered samples held under the same intensive conditions also produced scapolite mineral phase.

\section{Experimental details}

\subsection{Chemical analysis}

The chemical composition of the natural sample has been determined by Energy Dispersive Xray spectroscopy (EDX) (PGT IMIX-PTS detector on a JEOL-5800LV scanning electron microscope) for major elements and by Laser Ablation Induced Coupled Plasma Mass Spectrometry (LA-ICPMS) (Varian 820-MS) for minor elements and traces. For those analyses, cut sample was simply washed with ethanol. Powdered samples were put into epoxy resin and the surface was polished. EDX measurements were recorded with an electron beam of $15 \mathrm{kV}$ and a current of $5 \mathrm{nA}$. The internal reference used to calculate the sulfur concentration was $\mathrm{FeS}_{2}$. For LA-ICPMS, fluence of the ablating $193 \mathrm{~nm}$ laser was fixed at $4.54{\mathrm{~J} . \mathrm{cm}^{-2}}^{-50 \%}$ of the laser output). The ablated line roughly measures 300 x $110 \mu \mathrm{m}$. A pre-ablation was performed before each measurement to clean the surface of the sample. Since concentration ratios obtained by EDX and LA-ICPMS were similar, $\mathrm{FeS}_{2}$ was considered adequate for further chemical analysis of sulfur in scapolite.

\subsection{X-Ray Diffraction and structure analyses}

The structure was checked by XRD using a Bruker D8-Advance system working with a Cu source $\left(\lambda_{\mathrm{Cu}}=1.54059 \AA\right)$. Diffractograms were recorded between $15^{\circ}$ and $90^{\circ}$ in $2 \theta$ with a step of $1 \mathrm{~s}$ each $0.0118^{\circ}$. Diffractogram of sample P2 was recorded on an INEL diffractometer using Debye-Scherrer geometry because of low quantity obtained from HPHT synthesis. It was mounted 
in a $0.30 \mathrm{~mm}$ diameter capillary. Structure refinement was done on JANA software using Rietveld method with fundamental approach when possible.

\subsection{Spectroscopic methods}

Emission and excitation spectra were collected on a Fluorolog-3 (Horiba) with a photomultiplier detector. Powdered samples were placed into an Oxford cryostat to record spectra at liquid nitrogen temperature. Spectral band width and sampling interval were fixed at $1 \mathrm{~nm}$. Absorption spectra were recorded on a Perkin Elmer Lambda1050 UV-Visible-Near Infrared equipped with a $150 \mathrm{~mm}$ InGaAs integration sphere. Slits were fixed at $1 \mathrm{~nm}$ with an integration time of $0.52 \mathrm{~s}$ each $1 \mathrm{~nm}$. Both $100 \%$ and $0 \%$ reference spectra were collected for correction purposes. Infrared and Raman spectra were measured respectively on a Vertex 70 (Bruker) and FT-Raman Multiram (Bruker). For each Raman spectrum, 100 scans were recorded using $1000 \mathrm{~mW}$ power of the $1064 \mathrm{~nm}$ laser with a $1 \mathrm{~mm}$ opening of the diaphragm. The resolution was fixed at $4 \mathrm{~cm}^{-1}$. Infrared spectra were recorded on 100 scans between 400 and $4000 \mathrm{~cm}^{-1}$ with a resolution of $4 \mathrm{~cm}^{-1}$.

\subsection{Calculation method}

To confirm our assessments, theoretical calculations have been performed on simplified clusters (i.e. $\left[\mathrm{Na}_{4} \mathrm{~S}_{2}\right]^{\mathrm{x}+}$ ). To account for the interactions potentially felt by the clusters with respect to the outside atoms present in the true scapolite, a Polarizable Continuum Model (PCM, ethanol for which the dielectric constant $\varepsilon=24.85$ was enforced within the UFF cavities and an alpha parameter of 1.1$)^{3,4}$ has been added to our simulations. Clusters have been optimized and checked to be at a minimum on the potential energy surface (frequency calculations in the harmonic approximation) using the global hybrid PBE0 together with the triple- $\zeta$ Def2TZVP basis set at their ground states. ${ }^{5-}$

${ }^{7}$ In addition to structure relaxations in their GS, TD-DFT computations have been performed to 
optimize the excited states. Simulations of the luminescence properties have been performed using the Adiabatic Shift Paradigm. ${ }^{8-10}$ All the computations have been performed using the Gaussian $16^{11}$ suite and the post-treatments to plot spectra have been realized with the VMS package developed by Barone and co-workers. ${ }^{12}$ Several orientations of the $\mathrm{S}_{2}$ bond with respect to the $\mathrm{Na} 4$ planar-square-core have been tested. The perpendicular orientation has been found more favorable with respect to the others and thus we only discuss this one in the article text and the following. For the $\left[\mathrm{Na}_{4} \mathrm{~S}_{2}\right]^{2+}$ model, which corresponds to four $\mathrm{Na}^{+}$and one $\left(\mathrm{S}_{2}\right)^{2-}$, a minimum is reached in the $D_{4 h}$ local symmetry with the $\left(\mathrm{S}_{2}\right)^{2-}$ bond $(\mathrm{S}-\mathrm{S}=2.155 \AA)$ perfectly centered in the square formed by the four $\mathrm{Na}^{+}(\mathrm{Na}-\mathrm{Na}=3.689 \AA)$. The $\left[\mathrm{Na}_{4} \mathrm{~S}_{2}\right]^{3+}$ model is the combination of four $\mathrm{Na}^{+}$and one $\left(\mathrm{S}_{2}\right)^{-}$, leading to a doublet. In that electronic and structural configuration, the minimum is found in $C_{l}$ symmetry. The cluster strongly distorts toward a tetrahedron in which the Na-Na and S-S bond lengths are now around $4 \AA$ and $2.001 \AA$, respectively. For the $\left[\mathrm{Na}_{4} \mathrm{~S}_{2}\right]^{2+}$ a minimum is obtained in the $C_{2 v}$ symmetry in which the $[\mathrm{Na} 4]^{4+}$ cage is distorted with two short and two long Na-Na distances computed at 3.350 and $3.926 \AA$, respectively. In that conformation the S-S bond length increases dramatically and is calculated at $2.659 \AA$. For $\left[\mathrm{Na}_{4} \mathrm{~S}_{2}\right]^{3+}$ the S-S bond length is computed around $2.275 \AA$. On these grounds, the simulation of the luminescence spectra for both clusters has been performed using the so-called AS approach without temperature effects. This approach demonstrated its great accuracy when dealing with small to large rigid structures. ${ }^{13,14}$

All the simulated luminescence spectra were calculated using the Franck-Condon approximation taking into account the ground state vibrational frequencies. In order to reach a sufficient spectrum progression, the lowest normal modes were removed from the vibronic treatment. To limit the number of integrals to be taken into account, a class-based prescreening has been employed. ${ }^{15-17}$ In the present work, the spectra were computed with the following settings: 


$$
C_{1}^{\max }=70 ; C_{2}^{\max }=70 ; N_{I}^{\max }=100 \times 10^{8}
$$

To evaluate the normal modes responsible for the vibronic signature, the shift vector of all normal modes was analyzed. The shift-vector is described as the gradient of the final state projected onto the normal modes of the initial state.

\section{Characterization of natural and synthetic samples}

\subsection{X-Ray Diffraction}

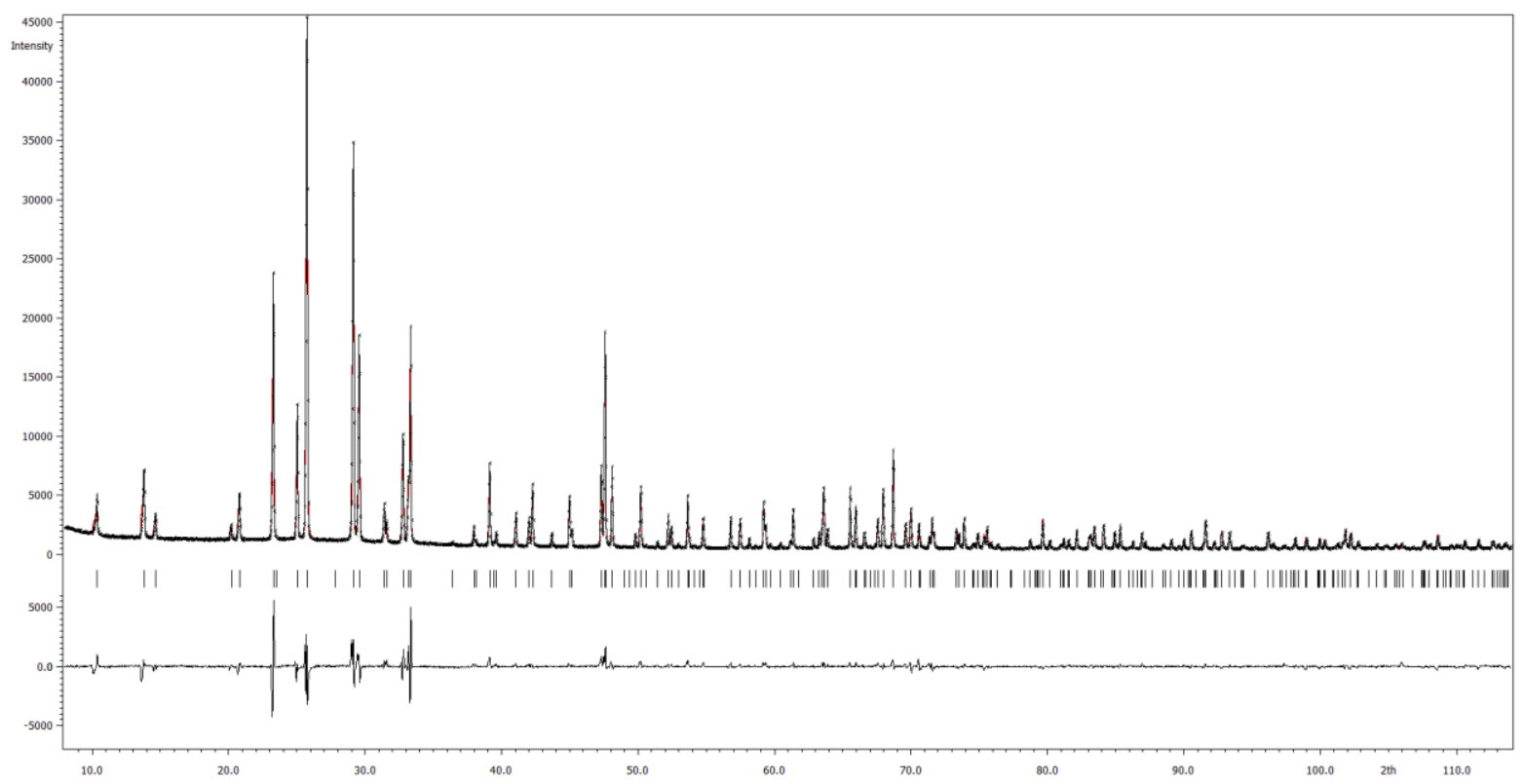

Fig.S2. Diffractogram of natural sample N1 in black with refined structure in red 


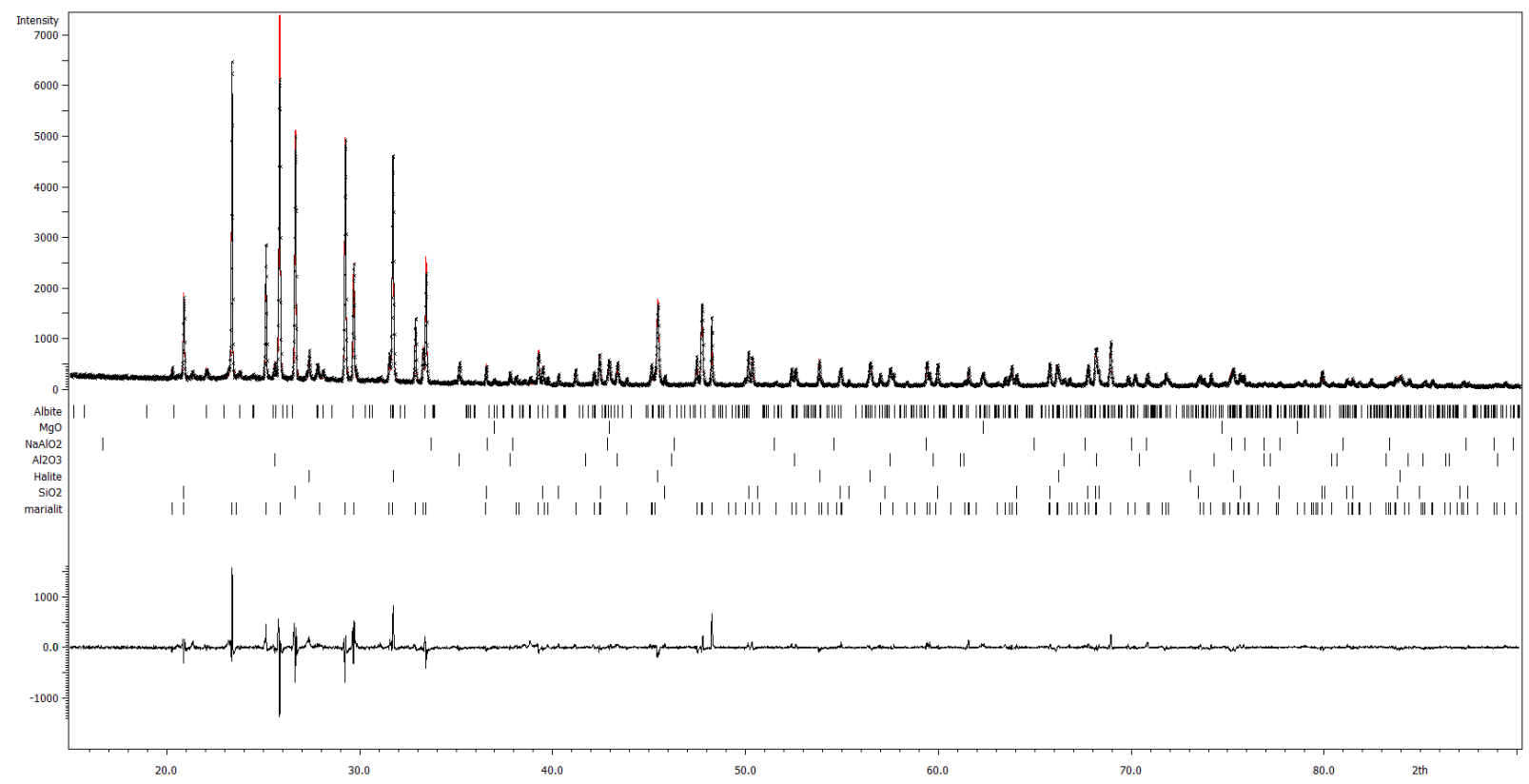

Fig. S3. Diffractogram of synthetic sample P1 in black with refinement including five phases giving the calculated envelop in red (hard to see as very close to the original data). The five phases are listed in Table S1.

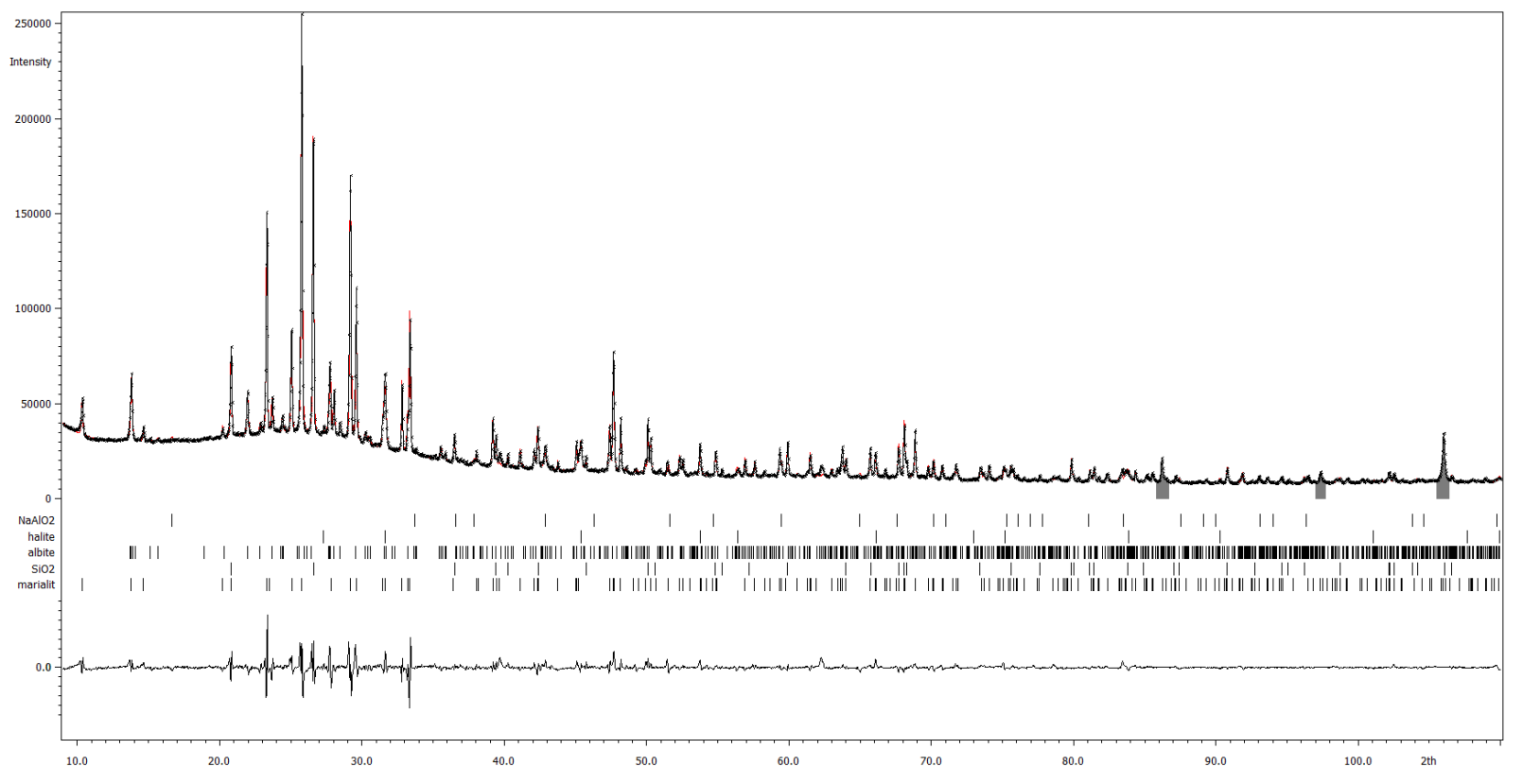


Fig. S4. XRD diffractogram of synthetic sample P2 in black with refinement of five phases giving the calculated envelop in red. Three grey zones correspond to peaks arising from the INEL detector and are excluded from refinement.

XRD diffractogram of $\mathrm{N} 1$ and synthetics samples have been successfully refined in the P42/n and $\mathrm{I} / \mathrm{m}$ space groups confirming the marialite structure. For both space groups, the structural model used included a statistical repartition of $\mathrm{Si}^{4+} / \mathrm{Al}^{3+}$ for all tetrahedral sites. Diffraction analyses on powdered samples does not allow a discrimination of these cations. However, since the luminescence properties have been studied here considering only the first neighbours ([Na4] sodium square plan) give the expected results, the influence of $\mathrm{Si}^{4+} / \mathrm{Al}^{3+}$ is considered negligible for now. Measured intensities are consistent with the chemical composition from EDX results implemented into the structural model. Refined cell parameters are about $\mathrm{a}=12.56 \AA$ and $\mathrm{c}=7.56$ $\AA$ for each sample.

\subsection{Energy Dispersive X-ray spectrometry}

EDX analysis of natural sample N1 gives a chemical formula $\left(\mathrm{Na}_{3,56} \mathrm{~K}_{0,44} \mathrm{Ca} 0,13\right) \mathrm{Al}_{3,08} \mathrm{Si}_{8.96} \mathrm{O}_{24}\left(\mathrm{Cl}_{1,01} \mathrm{~S}_{0,17}\right)$. This formula is very close to marialite species in the scapolite family. The density of N1 corroborates this result. Density has a direct relation with the composition of scapolite ${ }^{18}$. In the 30 other elements measured by LA-ICPMS, traces of $\mathrm{Br}, \mathrm{Ba}, \mathrm{Sr}$, $\mathrm{Rb}, \mathrm{Ga}$ and $\mathrm{Pb}$ (in order of decreasing concentration) have been found. Those trace elements are supposed to be included in the structure as substituting atoms. La-ICPMS have only be used for this natural sample N1. 
Results of XRD and EDX analyses are gathered in Table S1.

Table S1. characterization of the three undoped or sulfur-doped, synthetic scapolite samples

\begin{tabular}{|c|c|c|c|}
\hline $\begin{array}{l}\text { Sample } \\
\text { name }\end{array}$ & $\begin{array}{l}\text { Starting mixture } \\
\text { (quantities given in } \\
\text { mmol) }\end{array}$ & $\begin{array}{l}\text { Phases found by } \\
\text { XRD diagram } \\
\text { refinement }\end{array}$ & $\begin{array}{l}\text { EDX chemical composition of } \\
\text { marialite phase }\end{array}$ \\
\hline $\mathrm{P} 1$ & $\begin{array}{l}18 \mathrm{SiO}_{2}+3 \mathrm{Al}_{2} \mathrm{O}_{3}+ \\
3 \mathrm{Na}_{2} \mathrm{CO}_{3}+4 \mathrm{NaCl}\end{array}$ & $\begin{array}{c}\text { marialite }(65 \% \mathrm{w}) \\
\mathrm{SiO}_{2}(12 \% \mathrm{w}) \\
\mathrm{NaCl}(12 \% \mathrm{w}) \\
\mathrm{A} 12 \mathrm{O} 3(7 \% \mathrm{w}) \\
\mathrm{NaAlO} 2(3 \% \mathrm{w})\end{array}$ & $\mathrm{Na}_{3,74} \mathrm{Al}_{2.13} \mathrm{Si}_{9} \mathrm{O}_{22.71} \mathrm{Cl}_{0.71}$ \\
\hline $\mathrm{P} 2$ & $\begin{aligned} & 18 \mathrm{SiO}_{2}+3 \mathrm{Al}_{2} \mathrm{O}_{3}+1.5 \\
& \mathrm{Na}_{2} \mathrm{CO}_{3}+ 0.9 \mathrm{NaCl}+0.05 \\
& \mathrm{Na}_{2} \mathrm{~S}\end{aligned}$ & 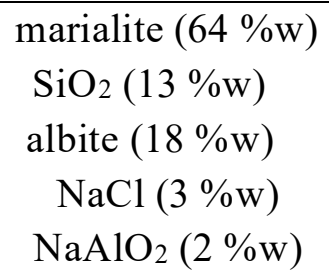 & 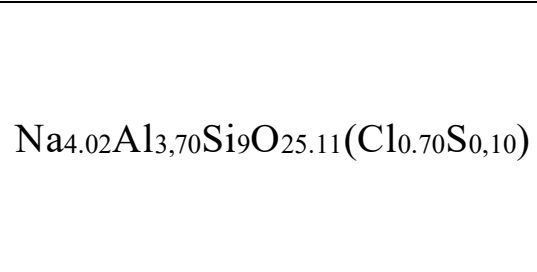 \\
\hline
\end{tabular}

\section{Spectroscopic considerations of $\left(\mathrm{S}_{2}\right)^{-}$ion}

3.1. Vibronic structure of luminescence analysis

Maxima positions of the vibronic structure were determined using the intersection of the first derivative with 0. All maxima are listed in Table S2. Mean values of all calculated bond lengths are $2.02 \AA$ and $1.92 \AA$ for diatomic and triatomic species respectively.

Table S2. Calculation of the S-S bond length using the vibronic structure of the emission 


\begin{tabular}{|c|c|c|c|c|c|}
\hline $\begin{array}{l}\text { Maxima } \\
\text { positions } \\
(\mathrm{nm})\end{array}$ & $\begin{array}{c}\text { Maxima } \\
\text { positions }(\mathrm{eV})\end{array}$ & $\begin{array}{c}\text { Difference } \\
\text { between two } \\
\text { successive maxima } \\
(\mathrm{meV})\end{array}$ & $\begin{array}{c}\text { Difference } \\
\text { between two } \\
\text { successive maxima } \\
\left(\mathrm{cm}^{-1}\right)\end{array}$ & $\begin{array}{c}\text { Calculate } \\
\text { d bond } \\
\text { length }(\AA)^{\mathrm{a}}\end{array}$ & $\begin{array}{c}\text { Calculate } \\
\text { d bond } \\
\text { length }(\AA)^{b}\end{array}$ \\
\hline 720.24 & 1.7217 & & & & \\
\hline 691.48 & 1.7933 & 71.60 & 577.5 & 2.02 & 1.93 \\
\hline 665.94 & 1.8620 & 68.78 & 554.7 & 2.04 & 1.95 \\
\hline 640.95 & 1.9346 & 72.59 & 585.5 & 2.02 & 1.92 \\
\hline 618.62 & 2.0045 & 69.85 & 563.4 & 2.04 & 1.94 \\
\hline 596.87 & 2.0775 & 73.05 & 589.2 & 2.01 & 1.92 \\
\hline 576.69 & 2.1502 & 72.69 & 586.3 & 2.01 & 1.92 \\
\hline 557.99 & 2.2223 & 72.04 & 581.0 & 2.02 & 1.93 \\
\hline 539.66 & 2.2977 & 75.48 & 608.8 & 1.99 & 1.90 \\
\hline 522.71 & 2.3723 & 74.53 & 601.1 & 2.00 & 1.90 \\
\hline 507.06 & 2.4455 & 73.21 & 590.5 & 2.01 & 1.92 \\
\hline
\end{tabular}

Bond lengths were compared to those found in literature (Table S3.).

Table S3. List of S-S bond lengths for different sulfur species.

\begin{tabular}{cccc}
$\begin{array}{c}\text { Sulfur } \\
\text { species }\end{array}$ & Host material & $\begin{array}{c}\text { S-S bond } \\
\text { length }(\AA)\end{array}$ & Reference \\
\hline$\left(\mathrm{S}_{2}\right)^{0}$ & $\mathrm{~S}_{2}($ calc. $)$ & 1.90 & 19 \\
$\left(\mathrm{~S}_{2}\right)^{-}$ & $\mathrm{CuS}_{2}$ & 2,03 & 20 \\
$\left(\mathrm{~S}_{2}\right)^{2-}$ & $\mathrm{Na}_{2} \mathrm{~S}_{2}$ & 2,15 & 21 \\
$\left(\mathrm{~S}_{3}\right)^{-}$ & $\mathrm{S}_{3}{ }^{-}($calc. $)$ & $2,02^{\mathrm{a}}$ & 22 \\
$\left(\mathrm{~S}_{3}\right)^{2-}$ & $\mathrm{Na}_{2} \mathrm{~S}_{3}$ & 2,08 & 21 \\
$\left(\mathrm{~S}_{4}\right)^{2-}$ & Zeolite $($ LTA) & 2,16 & 23
\end{tabular}

\subsection{Infrared spectra}

Infrared spectra of sample N1 were recorded in both Attenuated Total Reflectance (powdered part) and transmission (crystal part) modes. They are presented on Fig. S5. Since ATR is more 
adapted for lower energy and transmission for higher energy, spectral signatures are obviously different. Vibronic energy deduced with Steudel law is about $565 \mathrm{~cm}^{-1}$. Bands potentially corresponding to this vibrational energy are assigned to framework modes ${ }^{24}$.

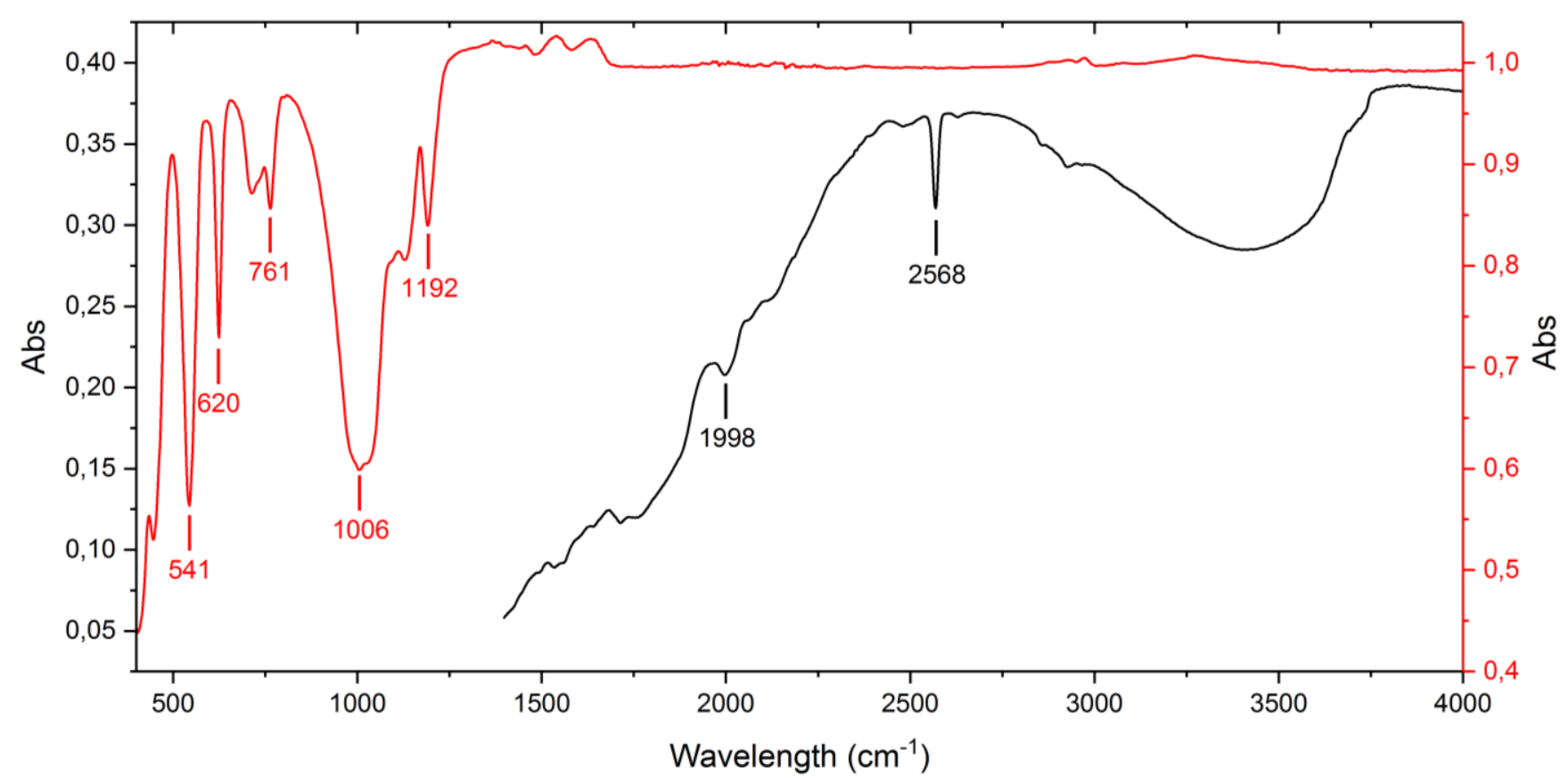

Fig.S5. Infrared spectra of natural sample N1 in ATR (red) and transmission (black) modes.

\subsection{Raman spectra}

As in infrared spectra, on all Raman spectra (Fig. S6), it appears that the expected $565 \mathrm{~cm}^{-1}$ band is covered by a band arising from the structure ${ }^{25}$ or possibly not intense enough. In the comparative nine rough natural samples, strong luminescence interferes with the Raman signal. 

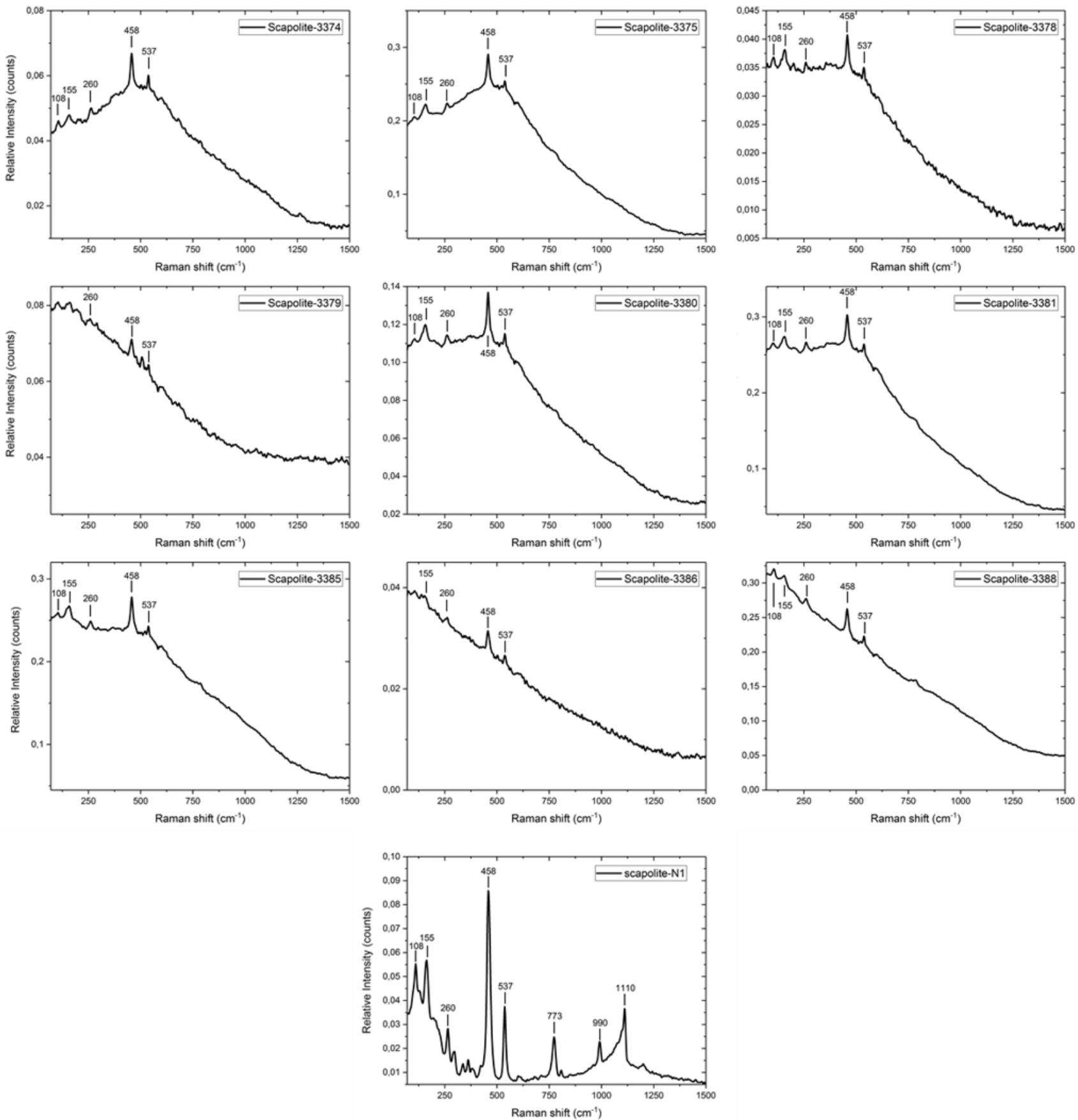

Fig. S6. Raman spectra of ten natural luminescent marialite scapolites. Beyond $1500 \mathrm{~cm}^{-1}$ there are only luminescence bands, no Raman signal.

\subsection{XPS Analyses}


X-ray photoelectron spectroscopy (XPS) analysis is able to differentiate between sulfur oxidation states in alumino-silicates ${ }^{26}$ and could give another experimental prove for the presence of $\left(\mathrm{S}_{2}\right)^{-}$so formally $\mathrm{S}^{0.5-}$ oxidation state. However, first attempts showed that the detection limit of XPS is too high to be able to record the $2 \mathrm{~s}$ or $2 \mathrm{p}$ levels of sulfur in natural and synthetic scapolites with confidence. Further analyses will be done on synthetic samples.

\section{References}

(1) Almeida, K. M. F.; Jenkins, D. M. Stability Field of the Cl-Rich Scapolite Marialite. Am. Mineral. 2017, 102 (12), 2484-2493. https://doi.org/10.2138/am-2017-6132.

(2) Morizet, Y.; Brooker, R. A.; Kohn, S. C. CO2 in Haplo-Phonolite Melt: Solubility, Speciation and Carbonate Complexation. Geochim. Cosmochim. Acta 2002, 66 (10), 18091820. https://doi.org/10.1016/S0016-7037(01)00893-6.

(3) Barone, V.; Cossi, M.; Tomasi, J. A New Definition of Cavities for the Computation of Solvation Free Energies by the Polarizable Continuum Model. J. Chem. Phys. 1997, 107 (8), 3210. https://doi.org/10.1063/1.474671.

(4) Cossi, M.; Scalmani, G.; Rega, N.; Barone, V. New Developments in the Polarizable Continuum Model for Quantum Mechanical and Classical Calculations on Molecules in Solution. J. Chem. Phys. 2002, 117 (1), 43. https://doi.org/10.1063/1.1480445.

(5) Adamo, C.; Barone, V. Toward Reliable Density Functional Methods without Adjustable Parameters: The PBE0 Model. J. Chem. Phys. 1999, 110 (13), 6158-6170. https://doi.org/10.1063/1.478522.

(6) Ernzerhof, M.; Scuseria, G. E. Assessment of the Perdew-Burke-Ernzerhof ExchangeCorrelation Functional. J. Chem. Phys. 1999, $110 \quad$ (11), 5029-5036. https://doi.org/10.1063/1.478401. 
(7) Weigend, F.; Ahlrichs, R. Balanced Basis Sets of Split Valence $\{$,$\} Triple Zeta Valence and$ Quadruple Zeta Valence Quality for H to Rn: Design and Assessment of Accuracy. Phys. Chem. Chem. Phys. 2005, 7 (18), 3297-3305. https://doi.org/10.1039/B508541A.

(8) Barone, V.; Baiardi, A.; Biczysko, M.; Bloino, J.; Cappelli, C.; Lipparini, F. Implementation and Validation of a Multi-Purpose Virtual Spectrometer for Large Systems in Complex Environments. Phys. Chem. Chem. Phys. 2012, 14 (36), 12404-12422. https://doi.org/10.1039/C2CP41006K.

(9) Barone, V.; Bloino, J.; Biczysko, M.; Santoro, F. Fully Integrated Approach to Compute Vibrationally Resolved Optical Spectra: From Small Molecules to Macrosystems. J. Chem. Theory Comput. 2009, 5 (3), 540-554. https://doi.org/10.1021/ct8004744.

(10) Vazart, F.; Latouche, C.; Bloino, J.; Barone, V. Vibronic Coupling Investigation to Compute Phosphorescence Spectra of Pt(II) Complexes. Inorg. Chem. 2015, 54 (11), 55885595. https://doi.org/10.1021/acs.inorgchem.5b00734.

(11) M. J. Frisch, G. W. Trucks, H. B. Schlegel, G. E. S.; M. A. Robb, J. R. Cheeseman, G. Scalmani, V. B.; G. A. Petersson, H. Nakatsuji, X. Li, M. Caricato, A. V. M.; J. Bloino, B. G. Janesko, R. Gomperts, B. Mennucci, H. P. H.; J. V. Ortiz, A. F. Izmaylov, J. L. Sonnenberg, D. W.-Y.; F. Ding, F. Lipparini, F. Egidi, J. Goings, B. Peng, A. P.; T. Henderson, D. Ranasinghe, V. G. Zakrzewski, J. Gao, N. R.; G. Zheng, W. Liang, M. Hada, M. Ehara, K. Toyota, R. F.; J. Hasegawa, M. Ishida, T. Nakajima, Y. Honda, O. Kitao, H. N.; T. Vreven, K. Throssell, J. A. Montgomery, Jr., J. E. P.; F. Ogliaro, M. J. Bearpark, J. J. Heyd, E. N. Brothers, K. N. K.; V. N. Staroverov, T. A. Keith, R. Kobayashi, J. N.; K. Raghavachari, A. P. Rendell, J. C. Burant, S. S. I.; J. Tomasi, M. Cossi, J. M. Millam, M. Klene, C. Adamo, R. C.; J. W. Ochterski, R. L. Martin, K. Morokuma, O. F.; J. B. Foresman, 
and D. J. Fox, Gaussian, Inc., Wallingford CT, 2016. Gaussian G16B01. 2016.

(12) Licari, D.; Baiardi, A.; Biczysko, M.; Egidi, F.; Latouche, C.; Barone, V. Implementation of a Graphical User Interface for the Virtual Multifrequency Spectrometer: The VMS-Draw Tool. J. Comput. Chem. 2015, 36 (5), 321-334.

(13) Belaidi, H.; Belaidi, S.; Katan, C.; Latouche, C.; Boucekkine, A. Vibronic Coupling to Simulate the Phosphorescence Spectra of Ir(III)-Based OLED Systems: TD-DFT Results Meet Experimental Data. J. Mol. Model. 2016, $22 \quad$ (11), 265. https://doi.org/10.1007/s00894-016-3132-8.

(14) Latouche, C.; Baiardi, A.; Barone, V. Virtual Eyes Designed for Quantitative Spectroscopy of Inorganic Complexes: Vibronic Signatures in the Phosphorescence Spectra of Terpyridine Derivatives. J. Phys. Chem. B 2015, 119 (24), 7253-7257. https://doi.org/10.1021/jp510589u.

(15) Santoro, F.; Improta, R.; Lami, A.; Bloino, J.; Barone, V. Effective Method to Compute Franck-Condon Integrals for Optical Spectra of Large Molecules in Solution. J. Chem. Phys. 2007, 126 (8). https://doi.org/10.1063/1.2437197.

(16) Santoro, F.; Lami, A.; Improta, R.; Barone, V. Effective Method to Compute Vibrationally Resolved Optical Spectra of Large Molecules at Finite Temperature in the Gas Phase and in Solution. J. Chem. Phys. 2007, 126 (18). https://doi.org/10.1063/1.2721539.

(17) Santoro, F.; Lami, A.; Improta, R.; Bloino, J.; Barone, V. Effective Method for the Computation of Optical Spectra of Large Molecules at Finite Temperature Including the Duschinsky and Herzberg-Teller Effect: The Qx Band of Porphyrin as a Case Study. J. Chem. Phys. 2008, 128 (22). https://doi.org/10.1063/1.2929846.

(18) Shaw, D. The Geochemistry of Scapolite, Part I. Previous Work and General Mineralogy. 
J. Petrol. 1960, 1 (2), 218-260.

(19) Wang, X.; Liang, B.; Andrews, L. Infrared Spectra and Density Functional Theory Calculations of Coinage Metal Disulfide Molecules and Complexes. Dalt. Trans. 2009, 21, 4190-4198. https://doi.org/10.1039/b902115a.

(20) King, H. E.; Prewitt, C. T. Structure and Symmetry of CuS2 (Pyrite Structure). Am. Mineral. 1979, 64 (11-12), 1265-1271.

(21) El Jaroudi, O.; Picquenard, E.; Demortier, A.; Lelieur, J. P.; Corset, J. Polysulfide Anions II: Structure and Vibrational Spectra of the (S4)2- and (S5)2- Anions. Influence of the Cations on Bond Length, Valence, and Torsion Angle. Inorg. Chem. 2000, 39 (12), 25932603. https://doi.org/10.1021/ic991419x.

(22) Tossell, J. A. Calculation of the Properties of the S3-Radical Anion and Its Complexes with $\mathrm{Cu}+$ in Aqueous Solution. Geochim. Cosmochim. Acta 2012, 95, 79-92. https://doi.org/10.1016/j.gca.2012.07.020.

(23) Lim, H. S.; Heo, N. H.; Seff, K. Disproportionation of an Element in a Zeolite. III. Crystal Structure of a High-Temperature Sulfur Sorption Complex of Zeolite LTA Containing Two New Ions: Perthiosulfite, S 42-, and the Trisulfur Cation, S 32+. J. Phys. Chem. C 2018, 122 (49), 28133-28141. https://doi.org/10.1021/acs.jpcc.8b09223.

(24) Swayze, G.; Clark, R. Infrared Spectra and Crystal Chemistry of Scapolites - Implications for Martian Mineralogy. J. Geophys. Res. 1990, 95 (B9), 14481-14495.

(25) Culka, A.; Jehlička, J. A Database of Raman Spectra of Precious Gemstones and Minerals Used as Cut Gems Obtained Using Portable Sequentially Shifted Excitation Raman Spectrometer. J. Raman Spectrosc. 2019, 50 (2), 262-280. https://doi.org/10.1002/jrs.5504.

(26) Tauson, V. L.; Goettlicher, J.; Sapozhnikov, A. N.; Mangold, S.; Lustenberg, E. E. Sulphur 
Speciation in Lazurite-Type Minerals (Na,Ca) 8[Al 6Si 6O 24](SO 4,S) 2 and Their Annealing Products: A Comparative XPS and XAS Study. Eur. J. Mineral. 2012, 24 (1), 133-152. https://doi.org/10.1127/0935-1221/2011/0023-2132. 